\title{
Identifying and Prioritizing Workplace Climate Predictors of Burnout Among VHA Primary Care Physicians
}

\author{
Ryan Sterling, $P h D^{7}$ (D), Seppo T. Rinne, $M D^{2}$, Ashok Reddy, $M D^{1,3}$, \\ Megan Moldestad, $\mathrm{MS}^{\mathrm{l}}$, Peter Kaboli, MD", Christian D. Helfrich, $\mathrm{PhD}{ }^{1,5}$, \\ Nora B. Henrikson, $\mathrm{PhD}^{6}$, Karin M. Nelson, $\mathrm{MD}^{7}$, Catherine Kaminetzky, $\mathrm{MD}^{7}$, and \\ Edwin S. Wong, $P h D^{1,5}$
}

\begin{abstract}
${ }^{1}$ Center for Veteran-Centered and Value-Driven Care, VA Puget Sound Health Care System, Seattle, WA, USA; ${ }^{2}$ VA Center for Healthcare Organization and Implementation Research, Bedford, MA, USA; ${ }^{3}$ Department of Medicine, Division of General Internal Medicine, University of Washington, Seattle, WA, USA; ${ }^{4}$ lowa City VA Medical Center and University of lowa, lowa City, IA, USA; ${ }^{5}$ Department of Health Services, University of Washington, Seattle, WA, USA; ${ }^{6}$ Kaiser Permanente Washington, Seattle, WA, USA.
\end{abstract}

OBJECTIVE: Burnout, or job-related stress, affects more than half of all US physicians, with primary care physicians (PCPs) experiencing some of the highest rates in medicine. Our study analyzes national survey data to identify and prioritize workplace climate predictors of burnout among PCPs within a large integrated health system.

DESIGN: Observational study of annual survey data from the Veterans Health Administration (VHA) All Employee Survey (AES) for 2013-2017. AES response rate ranged from 56 to $60 \%$ during the study period. Independent and dependent variables were measured from separate random samples. In total, 8,456 individual-level responses among PCPs at 110 VHA practice sites were aggregated at the facility level by reporting year. We used the semiautomated LASSO procedure to identify workplace climate measures that were more influential in predicting burnout and assessed relative importance using the Shapely value decomposition.

PARTICIPANTS: VHA employees that self-identify as PCPs.

MAIN MEASURES: Dependent variables included two dichotomous measures of burnout: emotional exhaustion and depersonalization. Independent measures included 30 survey measures related to dimensions of workplace climate (e.g., workload, leadership, satisfaction).

RESULTS: We identified seven influential workplace climate predictors of emotional exhaustion and nine predictors of depersonalization. With few exceptions, higher agreement/satisfaction scores for predictors were associated with a lower likelihood of burnout. The majority of explained variation in emotional exhaustion was attributable to perceptions of workload (32.6\%), organization satisfaction (28.2\%), and organization support (19.4\%). The majority of explained variation in depersonalization was attributable to workload (25.3\%), organization satisfaction (22.9\%), and connection to VHA mission (20.7\%).

CONCLUSION: Identifying the relative importance of workplace climate is important for the allocation of health organization resources to mitigate and prevent burnout

Received October 14, 2020

Accepted June 25, 2021

Published online July 29, 2021 within the PCP workplace. In a context of limited resources, efforts to reduce perceived workload and improve organization satisfaction may represent the biggest leverage points for health organizations to address physician burnout.

KEY WORDS: physician burnout; workplace climate; healthcare workforce.

$\mathrm{J}$ Gen Intern Med 37(1):87-94 DOI: $10.1007 / \mathrm{s} 11606-021-07006-\mathrm{x}$ (C) This is a U.S. government work and not under copyright protection in the U.S.; foreign copyright protection may apply 2021

\section{INTRODUCTION}

Current estimates project the United States (US) will experience a shortage of up to 55,200 primary care physicians (PCPs) by 2032. ${ }^{1}$ Growing demand for primary care comes from 76 million aging baby boomers, increasing rates of chronic disease, and recent expansion of health insurance coverage. ${ }^{2}$ As primary care demand continues to grow, the capacity to provide that care is dwindling: the number of PCPs leaving practice now exceeds the number entering, and more physicians are choosing to work part-time. ${ }^{3}$ Physician recruitment and retention are in part compromised by the fact that primary care is a high-stress profession. ${ }^{4}$

Burnout, or job-related stress, affects more than half of all US physicians, with PCPs experiencing among the highest rates in medicine. ${ }^{4,5}$ Burnout is characterized by emotional exhaustion, depersonalization (feelings of detachment and lack of empathy), and low personal achievement. ${ }^{6,7}$ In the Veterans Health Administration (VHA), one of the largest integrated health care systems in the USA, approximately $54 \%$ of PCPs report experiencing at least one symptom of burnout each week, followed by mental health (42\%) and emergency medicine physicians $(33 \%){ }^{4}$ The consequences of physician burnout are wide-ranging, including but not limited to increased medical errors, ${ }^{8}$ turnover, ${ }^{9,10}$ and reduced productivity. ${ }^{11}$ One recent US-based study estimated $\$ 4.6$ 
billion in annual costs attributable to burnout, primarily related to staff turnover and reductions in clinical hours. ${ }^{12}$

Although physician-level factors such as gender and age are sometimes found to be independent predictors of burnout, the primary drivers of physician burnout are largely tied to workplace factors. ${ }^{13-16}$ Workplace climate, defined as shared worker attitudes and perceptions of their work environment, is a leading determinant of physician burnout. ${ }^{17-19}$ While workplace climate research has been a key theme in the organizational and industrial psychology literature since the $1960 \mathrm{~s},{ }^{20}$ diverse views remain regarding a common set of constructs to conceptualize and measure workplace climate. ${ }^{21}$ It is challenging for researchers to offer a single and central view of its dimensions because workplace climate is highly situational. However, dimensions such as autonomy, support and warmth, leadership, reward, and risk, among others are commonly included in existing conceptual models measuring perception of climate ${ }^{17,22-34}$ Historically, the question of whether climate should be considered an individual experience construct or an attribute of the group or organization has also received attention in the climate research. The consensus among current research literature that climate is an attribute of the group or organization that can be measured based on the aggregation of individual perceptions of climate to a higher level of analysis. ${ }^{20,35,36}$

Although the association between workplace climate and physician burnout is well established, there is limited research exploring the relationship between physician burnout and distinct dimensions of workplace climate, and no prior research examines the relative importance of such factors in the context of the PCP workforce. In the coming years, the US physician workforce will need to serve a growing patient population with diminishing capacity to provide primary care. Being able to identify and prioritize specific and potentially modifiable workplace climate factors within an organizational setting will be crucial to identifying workplace interventions likely to yield the highest return on investment and guide the optimal allocation of scarce healthcare resources to mitigate and prevent PCP burnout. Our study addresses this need by identifying and prioritizing workplace climate predictors of physician burnout among PCPs employed by VHA nationwide. To achieve this goal, we developed a unique application of machine learning methods to understand the relative importance of 30 workplace climate variables in predicting burnout.

\section{METHODS}

\section{Study Population and Data}

This observational study examined data from the VHA All Employee Survey (AES) from 2013 to 2017. The AES is a voluntary, confidential, annual survey given to all VHA employees for the purposes of organizational feedback and action planning that includes questions on burnout and workplace climate. ${ }^{37}$ The AES response rate ranged from $56-60 \%$ during the period of interest. This response rate range is comparable to average rates reported in the organizational behavior literature among the healthcare sector $(54 \%)^{38}$ and higher than average rates among other large US government agencies during the same time period $(40 \%) .{ }^{39}$ We restricted AES responses to those completed by respondents that selfidentified as PCPs.

Individual respondents from the same survey source provided the measure for all study variables; in other words, we collected study data from the same rater and data source. To address artifactual correlation between predictor and outcome variables resulting from a common rater and source, we used a random sampling approach to construct our analytic sample (Fig. 1). We split respondent-level observations into equal random samples: in one sample, we dropped all covariate observations, and in the other, we dropped all outcome observations. We then appended the two random samples and aggregated individual responses to the facility level by reporting year to produce the final analytic sample. In this context, facilities are defined as VHA medical centers; survey responses affiliated with specific VHA clinic sites, such as community-based outpatient clinics, cannot be delineated in the AES data. Per AES data use requirements to protect the confidentiality of VHA employees, VHA facilities with fewer than ten outcome observations per reporting year were excluded from the analytic sample.

Ultimately, we examined aggregated facility-level observations from 110 VHA practice facilities nationwide, representing 8456 unique responses from employees who self-identified as PCPs. Prior to facility-level aggregation, we assessed inter-rater agreement among individual PCPs within VHA facilities. We consistently found intra-class correlations of greater than 0.1, indicating sufficient agreement across respondents at a given VHA facility. ${ }^{40}$

\section{Outcomes, Predictors, and Covariates}

Outcome variables measured emotional exhaustion and depersonalization using PCP responses to two AES questions. Prior research on physicians has found these two burnout domains to most strongly correlate with outcomes. ${ }^{41,42}$ The specific AES prompts included "I feel burned out from my work" (emotional exhaustion) and "I worry this job is hardening me emotionally" (depersonalization). For both prompts, respondents rated their degree of burnout using Likert-type scales ranging from 0 ("never" exhibiting symptoms of burnout) to 6 (experiencing symptoms of burnout "every day"). Single-item burnout measures have been applied previously in physician burnout studies and are shown to correlate well with the full Maslach Burnout Inventory (MBI), ${ }^{43}$ considered the gold standard for burnout assessment. Outcomes were treated as dichotomous measures, where exhibiting burnout symptoms once or more per week indicated burnout. The methodology we employed to dichotomize the AES scales and define the threshold for burnout is consistent with the wider physician burnout literature and has been previously validated and shown to correlate strongly with outcomes. ${ }^{43,44}$ 


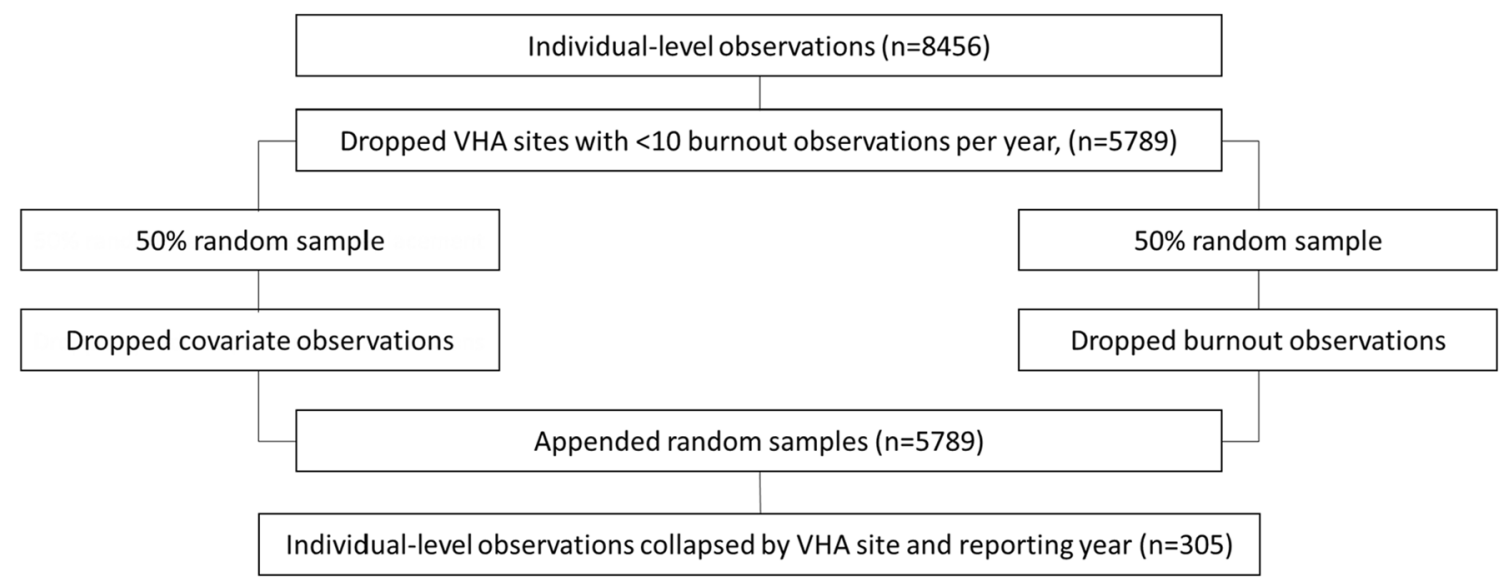

Figure 1 Construction of analytic sample.

Our predictors were derived from workplace climate dimensions identified in prior literature. ${ }^{17,21-34}$ Many foundational studies of workplace climate focus on dimensions of workload, leadership, organizational norms and values, communication, and cohesion. ${ }^{22-24}$ Because our analytical approach is data-driven, we wanted to considere a wide and diverse set of workplace climate factors to identify and prioritize predictors of physician burnout, leading us to further supplement our conceptual framework with other individual workplace climate factors found to be associated with physician burnout. In totality, the workplace climate dimensions considered in our analysis included conflict, recognition/reward, warmth, organizational norms/values, autonomy, growth opportunity, leadership, identity, physical/psychological safety, risk-taking, and workload (see Fig. 2). ${ }^{17,22-34}$ We mapped these dimensions to $30 \mathrm{AES}$ questions related to workplace climate to build our predictor set. Our study team reviewed this list to ensure all included survey items were worded such that that they could reasonably reflect a shared perception of workplace climate at the VHA facility level. (See Appendix A for a full description of AES items included in the analysis.) AES respondents rated their perceptions of each dimension of workplace climate using Likert-type scales of agreement/ satisfaction ranging from 1 ("not at all satisfied" / "strongly disagree") to 5 ("very satisfied" / "strongly agree"). Workplace climate predictors were treated as continuous measures, calculated as the average of responses within each facility-year unit. Finally, we extracted facility-level demographic covariates from survey data to control for potential confounding, including age, sex, and race/ethnicity among self-identified PCPs. Survey responses for all study variables were aggregated to the VHA facility level by reporting year.

\section{Statistical Analysis}

We described VHA facility-level characteristics using oneway tabulations of means and standard deviations. We used the semi-automated LASSO procedure to identify workplace climate predictors of burnout, with survey year and VHAfacility fixed effects. LASSO is a common approach in machine learning that performs both variable selection and regularization in order to enhance the prediction accuracy and

Workplace Climate Dimensions:
Conflict
Recognition/Reward
Warmth
Organizational Norms/Values
Autonomy
Growth Opportunity
Leadership
Identity
Physical/psychological Safety
Risk Taking
Workload

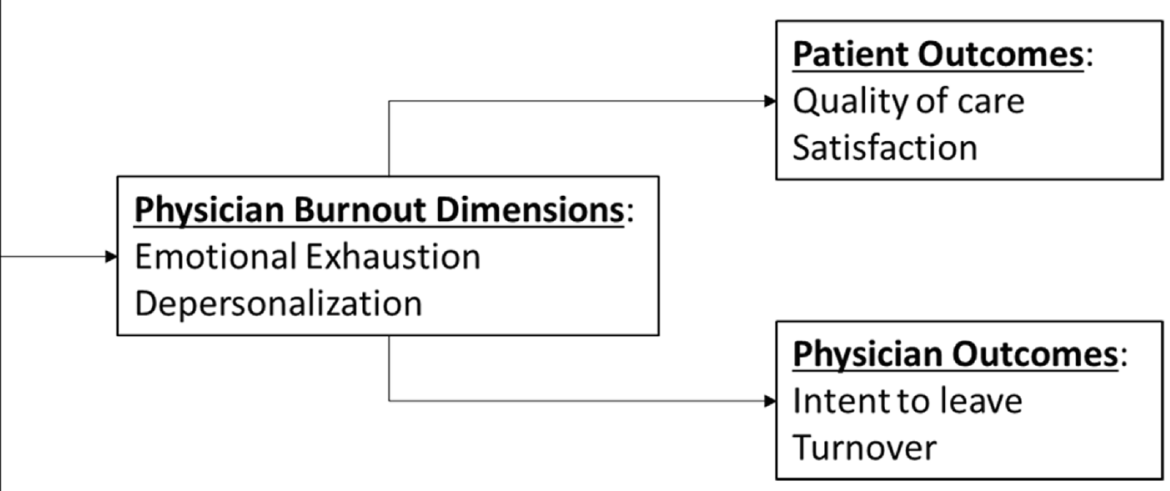

Figure 2 Conceptual model. 
interpretability of the statistical model it produces. ${ }^{45}$ This type of regression approach penalizes the absolute size of the regression coefficients; the larger the penalty, the further the estimates shrink towards zero such that some coefficients are eliminated, resulting in a more parsimonious model. We used the Extended Bayesian Information Criterion (EBIC) to select the best fit model. ${ }^{45}$ We reported adjusted LASSO estimators with bootstrapped estimate standard errors (based on 1000 bias-corrected bootstrap replications for all coefficients).

We examined the importance of workplace climate predictors using the Shapley value decomposition, which calculates mutually exclusive contributions of variation explained by the identified predictors of workplace climate. ${ }^{46,47}$ This approach addresses a limitation in other approaches whereby the sum of marginal contributions of variation explained across all explanatory variables is not $100 \%$ when variables are correlated. ${ }^{48}$ This approach partitions the total variation explained into contributions from each identified predictor to quantify the relative importance of each. ${ }^{47,48}$ The final Shapley value for a given predictor was calculated as the weighted average of all partial $\mathrm{R}^{2}$ values. All statistical analyses were performed using STATA/MP Version 15 (STATA Corporation, College Station, TX). The VA Puget Sound Health Care System Institutional Review Board approved this study.

\section{RESULTS}

\section{Descriptive Statistics}

Among a sample of 305 facility-year observations from 2013 to 2017, a facility-level average of $52.2 \%$ of PCPs self-identified as male, $58.9 \%$ White, and $57.8 \%$ were 50 years of age or more (Table 1). On average, the facility-level proportion of PCPs who worked at VHA for ten years or less was $65.4 \%$; approximately one-third worked at VHA for more than ten years. VHA care is provided through 18 regional Veterans Integrated Service Networks (VISN). All VISNs are represented in the study sample, with the strongest representation in southern and midwestern areas. A facility-level average of $65.5 \%$ of PCPs reported experiencing at least one symptom of emotional exhaustion each week, and $47.8 \%$ reported depersonalization. (See Appendix B for descriptive statistics of burnout measures using the original $0-6$ point AES scale.)

\section{Burnout Predictors}

Seven of 30 workplace climate variables were identified as predictors of emotional exhaustion by the LASSO model (Table 2). Predictors included workload, organizational satisfaction, organizational support, praise, employee development, psychological safety, and innovation (pseudo $\mathrm{R}^{2}$ for full model = 0.579 ). Nine of 30 workplace climate variables predicted depersonalization (Table 2). These predictors included workload, organizational satisfaction, connection to VA mission, job control, praise, work/family balance, quality of direct supervision,
Table 1 VHA Practice Site Characteristics

\begin{tabular}{|c|c|}
\hline Site characteristics & $\begin{array}{l}\text { Mean }(\mathrm{SD}) * \\
(N=305 \text { site-year observa- } \\
\text { tions })\end{array}$ \\
\hline Male & $52.5(20.5)$ \\
\hline \multicolumn{2}{|l|}{ Age } \\
\hline$<29$ years & $<1.0(2.4)$ \\
\hline 30 to 39 years & $11.2(14.2)$ \\
\hline 40 to 49 years & $26.3(16.3)$ \\
\hline 50 to 59 years & $35.0(16.8)$ \\
\hline $60+$ years & $22.8(15.2)$ \\
\hline \multicolumn{2}{|l|}{ Race } \\
\hline White & $58.9(24.0)$ \\
\hline Black & $5.9(9.1)$ \\
\hline Asian & $22.4(19.1)$ \\
\hline Other & $12.8(8.4)$ \\
\hline Hispanic & $6.9(27.8)$ \\
\hline \multicolumn{2}{|l|}{ VA tenure } \\
\hline$<1$ year & $10.7(7.5)$ \\
\hline $\mathrm{T}-5$ years & $30.5(14.3)$ \\
\hline $5-10$ years & $24.2(11.7)$ \\
\hline $10-15$ years & $17.6(6.2)$ \\
\hline $15+$ years & $17.5(6.2)$ \\
\hline \multicolumn{2}{|l|}{ Burnout } \\
\hline Emotional exhaustion & $65.5(25.6)$ \\
\hline Depersonalization & $47.8(20.3)$ \\
\hline \multirow{2}{*}{\multicolumn{2}{|c|}{$\begin{array}{l}\text { Workplace climate measures } \dagger \\
\text { Conflict }\end{array}$}} \\
\hline & \\
\hline Conflict resolution & $3.69(0.55)$ \\
\hline Recognition/reward & \\
\hline Praise & $2.99(0.65)$ \\
\hline Warmth & \\
\hline Collaboration & $3.46(0.57)$ \\
\hline Communication & $3.70(0.58)$ \\
\hline Cooperation & $3.77(0.56)$ \\
\hline Organizational support & $2.54(0.73)$ \\
\hline \multicolumn{2}{|l|}{ Organizational Norms/Values } \\
\hline Respect & $3.97(0.52)$ \\
\hline Diversity acceptance & $3.69(0.55)$ \\
\hline Ethnics & $3.90(0.59)$ \\
\hline Work/family balance & $3.47(0.65)$ \\
\hline Comfortable bringing up problems & $3.66(0.62)$ \\
\hline \multicolumn{2}{|l|}{ Autonomy } \\
\hline Job control & $2.80(0.74)$ \\
\hline \multicolumn{2}{|l|}{ Growth opportunity } \\
\hline Employee development & $3.13(0.67)$ \\
\hline Promotion opportunity & $2.88(0.60)$ \\
\hline \multicolumn{2}{|l|}{ Leadership } \\
\hline Encouraged to speak up & $3.45(0.69)$ \\
\hline Quality of direct supervision & $2.64(0.71)$ \\
\hline Supervisor performance goals & $2.90(0.69)$ \\
\hline Favoritism & $3.68(0.64)$ \\
\hline Advocate & $3.46(0.72)$ \\
\hline Fairness & $3.57(0.65)$ \\
\hline Relationship & $3.74(0.61)$ \\
\hline Competency & $3.84(0.52)$ \\
\hline \multicolumn{2}{|l|}{ Identity } \\
\hline Organization satisfaction & $2.91(0.72)$ \\
\hline $\begin{array}{l}\text { Connection to organization } \\
\text { mission }\end{array}$ & $4.15(0.43)$ \\
\hline Organizational commitment & $3.04(0.73)$ \\
\hline \multicolumn{2}{|l|}{ Physical/psychological safety } \\
\hline Safety climate & $3.37(0.64)$ \\
\hline Work resources & $3.27(0.61)$ \\
\hline \multicolumn{2}{|l|}{ Risk taking } \\
\hline Innovation & $2.96(0.63)$ \\
\hline Safe trying new things & $3.25(0.63)$ \\
\hline \multicolumn{2}{|l|}{ Workload } \\
\hline Workload & $2.69(0.81)$ \\
\hline
\end{tabular}

*Reported means are averages across facility means

*Workplace climate measure scores based on agreement/satisfaction scales ranging from 1 to 5 ("not at all satisfied" to "strongly disagree" / "very satisfied" to "strongly agree") 
Table 2 Workplace Climate Predictors of Emotional Exhaustion and Depersonalization

\begin{tabular}{lll}
\hline \hline Predictors & $\begin{array}{l}\text { Post-estimation } \\
\text { coefficient }\end{array}$ & $\begin{array}{l}\text { SE } \\
\text { approximation }\end{array}$ \\
\hline $\begin{array}{ll}\text { Predictors of emotional } \\
\text { exhaustion: }\end{array}$ & \\
$\quad$ Praise & 0.44 & 0.10 \\
Organizational support & 0.07 & 0.08 \\
Employee development & 0.09 & 0.08 \\
Encouraged to speak up & 0.10 & 0.09 \\
Organizational satisfaction & 0.20 & 0.08 \\
Innovation & -0.16 & 0.94 \\
Workload & 0.36 & 0.59 \\
Predictors of & & \\
depersonalization: & 0.13 & 0.10 \\
$\quad$ Praise & 0.14 & 0.07 \\
Work/family balance & 0.19 & 0.09 \\
$\quad$ Job control & 0.14 & 0.08 \\
Quality of direct & & \\
supervision & & 0.11 \\
Organizational satisfaction & 0.17 & 0.11 \\
Connection to VA & 0.02 & 0.9 \\
mission & & 0.09 \\
$\quad$ Encouraged to speak up & 0.05 & 0.06 \\
Innovation & -0.06 & \\
Workload & 0.26 &
\end{tabular}

psychological safety, and innovation (pseudo $\mathrm{R}^{2}$ for full model $=$ 0.536). For both LASSO models, apart from innovation, higher agreement/satisfaction scores for workplace climate predictors were associated with a lower likelihood of PCP burnout.

\section{Variable Importance}

Perceptions of workload had the greatest explained variation in emotional exhaustion (32.6\%), followed by organization satisfaction (28.2\%), and organization support (19.4\%) (Table 3). Other contributors included praise (7.8\%), employee development $(8.1 \%)$, encouraged to speak up (2.0\%), and innovation (1.9\%). For depersonalization, the largest component of ex-

Table 3 Shapley Value DECOMPOSITION Results for Emotional Exhaustion and Depersonalization

\begin{tabular}{lll}
\hline \hline Predictors & $\begin{array}{l}\text { Shapley } \\
\text { value }\end{array}$ & $\begin{array}{l}\text { Explained variation } \\
(\boldsymbol{\%})\end{array}$ \\
\hline Predictors of emotional & & \\
exhaustion: & 0.17 & 32.6 \\
Workload & 0.11 & 28.2 \\
Organizational satisfaction & 0.10 & 19.4 \\
Organizational support & 0.06 & 7.8 \\
Praise & 0.05 & 8.1 \\
Employee development & 0.05 & 1.9 \\
Encouraged to speak up & 0.04 & 1.9 \\
Innovation & $\mathbf{0 . 5 7 9}$ & $\mathbf{1 0 0 . 0 0}$ \\
Total & & \\
Predictors of & & \\
depersonalization: & 0.13 & 25.3 \\
Workload & 0.10 & 22.9 \\
Organizational satisfaction & 0.07 & 20.7 \\
Connection to VA mission & 0.06 & 11.4 \\
Job control & 0.05 & 9.6 \\
Praise & 0.04 & 9.1 \\
Work/family balance & 0.03 & $<1.0$ \\
Quality of direct supervision & 0.03 & $<1.0$ \\
Encouraged to speak up & 0.03 & $<1.0$ \\
Innovation & $\mathbf{1 0 0 . 0 0}$ \\
Total & $\mathbf{0 . 5 3 6}$ & \\
\hline
\end{tabular}

plained variation was attributable to workload (25.3\%), followed by organization satisfaction (22.9\%), and connection to VHA mission (20.7\%). Other contributors of depersonalization included job control (11.4\%), praise $(9.6 \%)$, work/family balance $(9.1 \%)$, quality of direct supervision $(<1 \%)$, encouraged to speak up $(<1 \%)$, and innovation $(<1 \%)$ (Table 3$)$.

\section{DISCUSSION}

This study prioritized the importance of a comprehensive set of workplace climate measures in predicting PCP burnout within a large integrated health system using a new application of machine learning methods. Our results suggest that many elements of workplace climate predict burnout among the PCP workforce. These findings are consistent with prior studies that have identified workplace climate as a core determinant of physician burnout. ${ }^{17-19}$ We identified perceived workload as the strongest predictor of both emotional exhaustion and depersonalization, followed by organization satisfaction. Both workload and job satisfaction have been previously identified as drivers of physician burnout within VHA and other healthcare organizations (workload specifically in primary care settings), ${ }^{49-52}$ but to our knowledge, their relative importance has never before been compared against other workplace climate predictors. We observed additional distinctions in our findings by individual dimension of burnout. Organizational support emerged as a uniquely influential predictor of emotional exhaustion, while connection to institutional mission emerged as a uniquely influential predictor of depersonalization. Collectively, these findings can help decisionmakers prioritize interventions and system-level changes that target different aspects of workplace climate.

Our research suggests interventions that reduce perceived PCP workload may have the largest impact on burnout. While our study did not allow us to pinpoint what aspects of their day-today workload are most stressful to physicians, the current research highlights the increasing demands placed on PCPs such as long hours, complex electronic health record (EHR) systems, and other clinical burdens. ${ }^{30}$ Regarding potential solutions to address excess PCP workload, task delegation to other primary care staff may present a viable option. ${ }^{49,50}$ Prior research among PCPnurse dyads in primary care suggests task delegation is associated with less burnout for PCPs. ${ }^{49}$ However, delegation strategies must also consider the potential inadvertent increase of burnout among nurses and other ancillary staff who serve important roles in the provision of primary care alongside physicians. Improved usability of EHRs has also been identified as a potential mechanism to reduce physician workload. ${ }^{53}$ In addition, the use of physician scribes may serve as a potential solution to address EHR-related burdens and other workload stressors. ${ }^{53,54}$ Medical scribes are trained personnel who provide physicians with documentation assistance and perform other EHR tasks; their use in primary care settings has been associated with significant reductions in EHR documentation time and improvements in productivity. ${ }^{53,54}$ 
Based on our research, an additional point of leverage to address physician burnout may lie in efforts to increase organization satisfaction among physicians. Indeed, practice and policy changes to promote satisfaction have been shown to promote physician well-being and improve burnout, focusing on promoting shared core values, protecting physicians' time with patients, and promoting physician communities, among others. $^{55,56}$ This set of potential strategies particularly coincides with our findings around organizational support and connection to institutional mission, which were found to be uniquely influential predictors of emotional exhaustion and depersonalization, respectively. Both predictors speak to the importance of shared organizational values, sense of wellbeing, and spirit of shared community to have been previously linked to physician satisfaction. Regarding individual-level solutions to promote organization satisfaction among PCPs, these may focus on mindfulness, stress management and resiliency training, and positive coping strategies. ${ }^{42}$

As health organizations work to recruit, retain, and support their physician workforce in the context of diminishing capacity to provide primary care, our research offers an important contribution to the practice literature by providing an evidence-based prioritization of workplace climate factors. By pinpointing workload and organization satisfaction as the most influential predictors of PCP burnout among a wide range of climate factors, our findings help to guide the allocation of health organization resources to where they may have the greatest impact on mitigation and prevention of burnout within the PCP workforce. Fortunately, as discussed above, prior research already offers a number of specific practice and policy solutions that health organizations can employ to specifically target workload and organization satisfaction among the PCP workforce, including task delegation, the use of physician scribes, and improved usability of EHRs, among others. While not yet well understood, these strategies may also help organizations with PCP recruitment and retention of new PCPs, particularly for organizations such as VHA where nearly one-quarter of physicians in primary care are $>60$ years old and approaching retirement.

\section{LIMITATIONS}

Several limitations of this study need acknowledgement. First, the objective of this study was to prioritize predictors of PCP burnout; thus, findings should not be interpreted as causal. Second, by collecting independent and dependent variables from the same AES data source, survey participant, and survey year, our findings may be prone to common methods bias. However, our random sampling approach helps to address this problem by breaking the link between outcome and covariate responses collected from the same survey participant. Third, our dataset did not include individual identifiers, which prevented the tracking of individual PCP responses over time. This also limited our ability to identify and account for PCPs who may work a portion of their time outside of VHA, which could have impacted their reporting of perceived burnout. Fourth, we did not account for potential selection bias resulting from PCPs most affected by burnout being more (or less) likely to complete the AES survey, compared to PCPs less affected by burnout. However, given the relatively high AES response rate, we can be reasonably confident the scores are representative of VA employees' workplace perceptions and experiences. Lastly, our study focuses on data collected from PCPs from VHA, which has many unique institutional characteristics and may limit generalization to other practice settings. However, we constructed a robust analytic sample given that VHA is the largest health system in the USA and our sample includes medical facility sites nationwide.

\section{CONCLUSION}

The rising prevalence of burnout adversely affects physicians, patients, and healthcare organizations. Although physicianlevel factors play a role, drivers of burnout are largely tied to organization-related factors such as workplace climate. As the COVID-19 pandemic places acute strain on the US physician workforce, organizations are under even greater pressure to implement effective burnout mitigation and prevention strategies. Our findings identified perceptions of workload as the most influential workplace climate dimension among PCPs, followed by organization satisfaction. Moving forward, healthcare organizations deploying strategies to address burnout may consider targeting these priority workplace climate factors to best optimize scarce resources. Future studies should extend this analysis to different demographic sub-populations, practice locations, medical specialties, and team structures to understand potential differences in variable importance across physician populations and practice environments.

Acknowledgements: We wish to acknowledge the contributions of the VHA National Center for Organization Development. The authors also thank three anonymous reviewers for their helpful comments.

Corresponding Author: Ryan Sterling, PhD; Center for VeteranCentered and Value-Driven Care, VA Puget Sound Health Care System, Seattle, WA, USA (e-mail: ryan.sterling@va.gov).

Supplementary Information The online version contains supplementary material available at https://doi.org/10.1007/s11606-02107006- $x$.

Funding This study was funded by VA Health Services Research and Development Award IIR 15-363.

\section{Declarations:}

Conflict of Interest: The authors declare that they do not have a conflict of interest.

Disclaimer: The views expressed here are solely those of the authors and do not necessarily represent the position of the Veterans Health Administration, United States government, or authors' respective academic institutions. 


\section{REFERENCES}

1. HIS Market. The complexities of physician supply and demand: Projections from 2016 to 2030. Updated 2017. Accessed October 6, 2020 https://aamc-black.global.ssl.fastly.net/production/media/filer_public/ a5/c3/a5c3d565-14ec-48fb-974b-99fafaeecb00/aamc_projections_update_2017.pdf

2. Bodenheimer TS, Smith MD. Primary care: proposed solutions to the physician shortage without training more physicians. Health Affairs. 2013;32(11):1881-6.

3. Schwartz, MD. Health care reform and the primary care workforce bottleneck. Journal of general internal medicine. 2012;27(4): 469-72.

4. Shanafelt TD, Boone S, Tan $\mathbf{L}$, et al. Burnout and satisfaction with work-life balance among US physicians relative to the general US population. Archives of internal medicine. 2012;172(18):1377-85

5. Rinne ST, Mohr DC, Swamy L, et al. National Burnout Trends Among Physicians Working in the Department of Veterans Affairs. Journal of general internal medicine. 2020;35:1382-88.

6. Maslach C, Jackson SE, Leiter MP. Maslach Burnout Inventory Manual, 3rd ed. Palo Alto, CA: Consulting Psychologists Press; 1996.

7. Schaufeli WB, Leiter MP, Maslach C. Burnout: 35 years of research and practice. Career Dev Int. 2009;14(3):204-20.

8. Shanafelt TD, Balch CM, Bechamps G et al. Burnout and medical errors among American surgeons. Ann Surg. 2010;251(6):995-1000.

9. Shanafelt TD, Sloan J, Satele D, et al. Why do surgeons consider leaving practice? J Am Coll Surg. 2011;212(3): 421-2

10. Shanafelt TD, Raymond M, Kosty M, et al. Satisfaction with work-life balance and the career and retirement plans of US oncologists. $J$ Clin Oncol. 2014:32(11):1127-35.

11. Dewa CS, Loong D, Bonato S, et al. How does burnout affect physician productivity? A systematic literature review. BMC Health Serv Res. 2014;14(1): 325 .

12. Han, $\mathbf{S}$, et al. Estimating the attributable cost of physician burnout in the United States. Annals of internal medicine. 2019;170(11):784-90.

13. Shanafelt TD, West CP, Sloan JA, et al. Career fit and burnout among academic faculty. Arch Intern Med. 2009;169(10):990-5.

14. West CP, Shanafelt TD, Kolars JC. Quality of life, burnout, educational debt, and medical knowledge among internal medicine residents. JAMA. 2011;306(9): 952-60.

15. Shanafelt TD, Noseworthy JH. Executive leadership and physician wellbeing: nine organizational strategies to promote engagement and reduce burnout. Mayo Clin Proc. 2016:92(1):129-46.

16. Brazeau CM, Shanafelt T, Durning SJ, et al. Distress among matriculating medical students relative to the general population. Acad Med. 2014;89(11):1520-5.

17. Shanafelt TD, Gorringe G, Menaker R, et al. Impact of organizational leadership on physician burnout and satisfaction. Mayo Clin Proc. 2015;90(4):432-40.

18. Williams ES, Konrad TR, Linzer $\mathbf{M}$ et al. Physician, practice, and patient characteristics related to primary care physician physical and mental health: results from the Physician Worklife Study. Health Serv Res. 2002;37(1):119-41

19. Linn LS, Brook RH, Clark VA, et al. Physician and patient satisfaction as factors related to the organization of internal medicine group practices. Med Care. 1985;23(10):1171-8.

20. Schneider B, Ehrhart MG, Macey W. Organizational climate and culture. Annual review of psychology. 2013;64: 361-388.

21. Kundu, $\mathbf{K}$. Development of the conceptual framework of organizational climate. (2007).

22. Social Process \& Behavioral Issues. Organizational Climate. Updated 2020. Access October 6, 2020. https://hmhub.me/organizationalclimate/

23. Svyantek DJ, Bott JP. Organizational culture and organizational climate measures: An integrative review. In: Thomas JC, ed. Comprehensive handbook of psychological assessment, Volume 4. John Wiley \& Sons, Inc.; 2004.

24. Litwin G, Stringer R. Motivation and Organizational Climate. Cambridge: Harvard University Press; 1968.

25. Schneider B, Bartlett C. Individual Differences and Organizational Climate I: The Research Plan and Questionnaire Development. Personnel Psychology. 1968:21:323-34.

26. James LR, Jones AP. Organizational climate: A review of theory and research. Psychological bulletin. 1974:81(12):1096.

27. Linzer M, Gerrity M, Douglas JA, et al. Physician stress: results from the physician worklife study Stress and Health. 2002;18(1):37-42.
28. Linzer M, Baier ML, Mundt M, et al. Organizational climate, stress, and error in primary care: the MEMO study. Advances in patient safety: from research to implementation. 2005;1: 65-77.

29. Shanafelt TD, Sloan JA, Habermann TM. The well-being of physicians. The American journal of medicine. 2003;114(6):513

30. Shanafelt, TD, Dyrbye LN, Sinsky C, et al. Relationship between clerical burden and characteristics of the electronic environment with physician burnout and professional satisfaction. Mayo Clinic Proceedings. 2016;91(7):836-48.

31. Dyrbye, LN, West CP, Burriss TC, et al. Providing primary care in the United States: the work no one sees. Archives of internal medicine. 2012;172(18):1420-21.

32. Balch CM, Shanafelt TD, Dyrbye L, et al. Surgeon distress as calibrated by hours worked and nights on call. Journal of the American College of Surgeons. 2010;211(5):609-19.

33. Richter A, Kostova P, Baur X, et al. Less work: more burnout? A comparison of working conditions and the risk of burnout by German physicians before and after the implementation of the EU Working Time Directive. International Archives of Occupational and Environmental Health. 2014;87(2):205-15.

34. Williams ES, Konrad TR, Linzer M. Physician, practice, and patient characteristics related to primary care physician physical and mental health: results from the Physician Worklife Study. Health services research. 2019;37(1):119.

35. Madhukar V, and Sharma S. Organisational Climate: A Conceptual Perspective. Article in International Journal of Management and Business (2017)

36. James, LR., et al. Organizational and psychological climate: A review of theory and research. European Journal of work and organizational psychology. 2018; 17(1): 5-32.

37. Osatuke K, Draime J, Moorse SC, et al. Organization development in the Department of Veterans Affiars. In: Miller T, ed. The Praeger handbook of Veterans Health: History, challenges, issues and developments, Volume IV: Future directions in Veterans healthcare. Santa Barbara: Praeger; 2012:21-76

38. McLeod, CC., et al. Health care provider surveys in the United States, 2000-2010: a review. Evaluation \& the health professions. 2013;36(1):106-126

39. Office of Personal Management. Federal employee viewpoint survey: Government management report. 2020. Accessed June 16, 2021 https://www.opm.gov/fevs/reports/governmentwide-reports/ governmentwide-management-report/governmentwide-report/2020/ 2020-governmentwide-management-report.pdf

40. LeBreton, JM and Senter JL. Answers to 20 questions about interrater reliability and interrater agreement. Organizational research methods. 2008:11(4): 815-852.

41. Schaufeli W, Bakker A, Hoogduin K, et al. On the clinical validity of the Maslach burnout inventory and the burnout measure. Psychol Health. 2001;16(5):565-82.

42. West, CP, Liselotte NL, Tait . Physician burnout: contributors, consequences and solutions. Journal of internal medicine. 2018;283(6):516-29.

43. West CP, Dyrbye LN, Satele DV, et al. Concurrent validity of single-item measures of emotional exhaustion and depersonalization in burnout assessment. J Gen Intern Med. 2012;27(11):1445-52.

44. Dewa CS, Loong D, Bonato S, Trojanowski L. The relationship between physician burnout and quality of healthcare in terms of safety and acceptability: a systematic review. BMJ open. 2017:7(6):e015141.

45. Chen $\mathbf{J}$, Chen $\mathbf{Z}$. Extended Bayesian information criteria for model selection with large model spaces. Biometrika. 2008;95(3):759-71.

46. Shorrocks AF. Decomposition procedures for distributional analysis: a unified framework based on the Shapley value. $J$ Econ Inequal. 2013;11:99-126.

47. Israeli $\mathbf{O}$. A Shapley-based decomposition of the R-square of a linear regression. J Econ Inequal. 2007;5:199-212.

48. Gromping U. Estimators of Relative Importance in Linear Regression Based on Variance Decomposition. Am Stat. 2007:61(2):139-147.

49. Edwards, ST., et al. Task delegation and burnout trade-offs among primary care providers and nurses in Veterans Affairs Patient Aligned Care Teams (VA PACTs). The Journal of the American Board of Family Medicine. 2018;31(1): 83-93.

50. Helfrich, CD., et al. The association of team-specific workload and staffing with odds of burnout among VA primary care team members. Journal of general internal medicine. 2017;32(7): 760-766.

51. Shanafelt, TD., et al. Burnout and career satisfaction among American surgeons. Annals of surgery. 2019;250(3): 463-471. 
52. Pérez, T. Chivato, et al. "Professional burnout and work satisfaction in Spanish allergists: analysis of working conditions in the specialty." $J$ Investig Allergol Clin Immunol 21.1 (2011): 13-21.

53. Shanafelt, TD and Noseworthy JH. Executive leadership and physician well-being: nine organizational strategies to promote engagement and reduce burnout. Mayo Clinic Proceedings. 2017;92(1).

54. Pozdnyakova, A., et al. Impact of medical scribes on physician and patient satisfaction in primary care. Journal of general internal medicine. 2018;33(7): 1109-1115.

55. West CP, Dyrbye LN, Rabatin JT et al. Intervention to promote physicians well-being, job satisfaction, and professionalism: a randomized clinical trial. JAMA Intern Med. 2014;174:527-33.
56. West CP, Dyrbye LN, Satele D, Shanafelt TD. A randomized controlled trial evaluating the effect of COMPASS (Colleagues Meeting to Promote and Sustain Satisfaction) small group sessions on physician well-being, meaning, and job satisfaction. J Gen Intern Med. 2015;30(2):45

Publisher's Note: Springer Nature remains neutral with regard to jurisdictional claims in published maps and institutional affiliations. 